ADVERSE DRUG REACTION

\title{
A case of two adverse reactions
}

\author{
L-A Smith, M Harkness
}

Postgrad Med J 2004;80:484-486. doi: 10.1136/pgmj.2003.017020

Low molecular weight heparins are now widely prescribed in the treatment of thromboembolic disease and acute coronary syndromes. Anaphylaxis is a recognised but rare potentially life threatening side effect of heparin.

Common clinical features of anaphylaxis are cardiovascular collapse, bronchospasm, cutaneous symptoms, angioedema, generalised oedema, or gastrointestinal symptoms. It is extremely rare, however, for patients to experience such dramatic and potentially life threatening consequences as seen in the case reported here. It has been shown that patients may be tolerant of certain low molecular weight heparins but sensitive to others.

Adrenaline is regarded as the most important drug for any severe anaphylactic reaction. Administration by the intramuscular route produces significantly higher peak plasma concentrations compared with subcutaneous injection, which is clearly beneficial in the critically compromised patient. Current UK Resuscitation Council guidelines support the use of $0.5 \mathrm{ml}$ of $1: 1000$ adrenaline to be administered intramuscularly.

A 78 year old man with a history of ischaemic heart disease (positive exercise test at end of stage 1 of Bruce protocol) was referred to the coronary care unit by his general practitioner. He had been having increasing frequency and severity of angina for one week. His admission was precipitated by an episode of severe pain unrelieved by sublingual glycerine trinitrate spray.

Past medical history included treated hypertension, carcinoma of prostate, and a femoral deep venous thrombosis. He had been treated three years previously with tinzaparin (without any adverse effects) followed by anticoagulation with warfarin.

His medications on admission included atenolol $100 \mathrm{mg}$ once a day, frusemide $40 \mathrm{mg}$ once a day, amlodipine $10 \mathrm{mg}$ once a day, fosfestrol tetrasodium $120 \mathrm{mg}$ twice a day, goserelin by injection every three months, isosorbide mononitrate $40 \mathrm{mg}$ twice a day, cyclizine $50 \mathrm{mg}$ three times a day, aspirin $75 \mathrm{mg}$ once a day, and lisinopril $2.5 \mathrm{mg}$ once a day. He was known to have had a previous sensitivity reaction to pethidine, but there was no previous history of angioedema.

On admission, his pain had lessened after having diamorphine already administered by his general practitioner and was fully relieved by $3 \mathrm{mg}$ sublingual buccal suscard. The paramedic crew had given $300 \mathrm{mg}$ aspirin. Admission 12 lead electrocardiogram (ECG) showed anterolateral ischaemia (fig 1).

The patient was started on intravenous nitrate and subcutaneous enoxaparin at treatment dose ( $1 \mathrm{mg} / \mathrm{kg}$ body weight twice daily). Thirty minutes later, the patient himself noted marked tongue swelling. Following review by the attending senior house officer he was given oxygen, $200 \mathrm{mg}$ hydrocortisone and $10 \mathrm{mg}$ chlorpheniramine intravenously. The patient continued to develop worsening angioedema. He developed a bradycardia and hypotension despite the nitrate infusion having been stopped. He was prescribed $1 \mathrm{ml}$ of 1:1000 adrenaline, given subcutaneously. The administration of adrenaline had rapid clinical effect and haemodynamic stability was regained. The angioedema had fully resolved within two hours from onset.

After resolution of the angioedema, the patient developed severe chest pain, requiring large doses of intravenous nitrates and diamorphine. His ECG showed more marked widespread ST depression (fig 2). Electrocardiographic changes persisted for four hours after the administration of adrenaline. Troponin I was raised at $18.9 \mu \mathrm{g} / \mathrm{l}$ ( $>1.0$ high risk) at 12 hours.

He was referred to a tertiary centre where he underwent coronary angiography, which showed triple vessel disease with an occluded right coronary artery, circumflex, left main stem stenosis, and severe left anterior descending artery disease. The pattern of disease was deemed unsuitable for revascularisation by percutaneous intervention or surgical grafting. The patient was optimised on medical treatment. He successfully completed cardiac rehabilitation after discharge and remained well at outpatient review six months later. Unfortunately he suffered a further cardiac event and died one year after the episode of angioedema. This suspected adverse drug reaction to enoxaparin was reported to the Committee on Safety of Medicines.

\section{DISCUSSION}

Low molecular weight heparins are now widely prescribed in the treatment of thromboembolic disease and acute coronary syndromes. Side effects include haemorrhage, eczematous plaque formation at the injection site, ${ }^{1}$ skin necrosis, ${ }^{2}$ thrombocytopenia, and hypersensitivity reactions (including urticaria, ${ }^{3}$ angioedema, ${ }^{3}$ and anaphylaxis $\left.{ }^{4}\right)$. It is extremely rare, however, for an individual to experience such a dramatic and potentially life threatening adverse reaction to heparin as seen in the case that we report.

Angioedema is a rare (incidence $0.1 \%-0.2 \%$; with a threefold risk in the black population) adverse reaction to angiotensin converting enzyme (ACE) inhibitors. Most reactions occur within a few hours or in the first week after therapy, although delayed onset of months or years has also been described. Certain drugs such as ciprofloxacin, amoxycillin, mefanamic acid, and injection of lignocaine as a local anaesthetic have been postulated as co-factors in cases having a delayed onset. ${ }^{5}$ It was felt that this man's adverse reaction was probably not due to the ACE inhibitor. It is not known whether he was taking an ACE inhibitor when treated with tinzaparin as his general practitioner records were unavailable and the deep venous thrombosis had been treated elsewhere. He had no further episodes of angioedema, having continued on and been discharged on lisinopril. At the tertiary unit, he was anticoagulated with lepirudin (a recombinant hirudin). He declined any further investigation

Abbreviations: $A C E$, angiotensin converting enzyme; $E C G$, electrocardiogram 

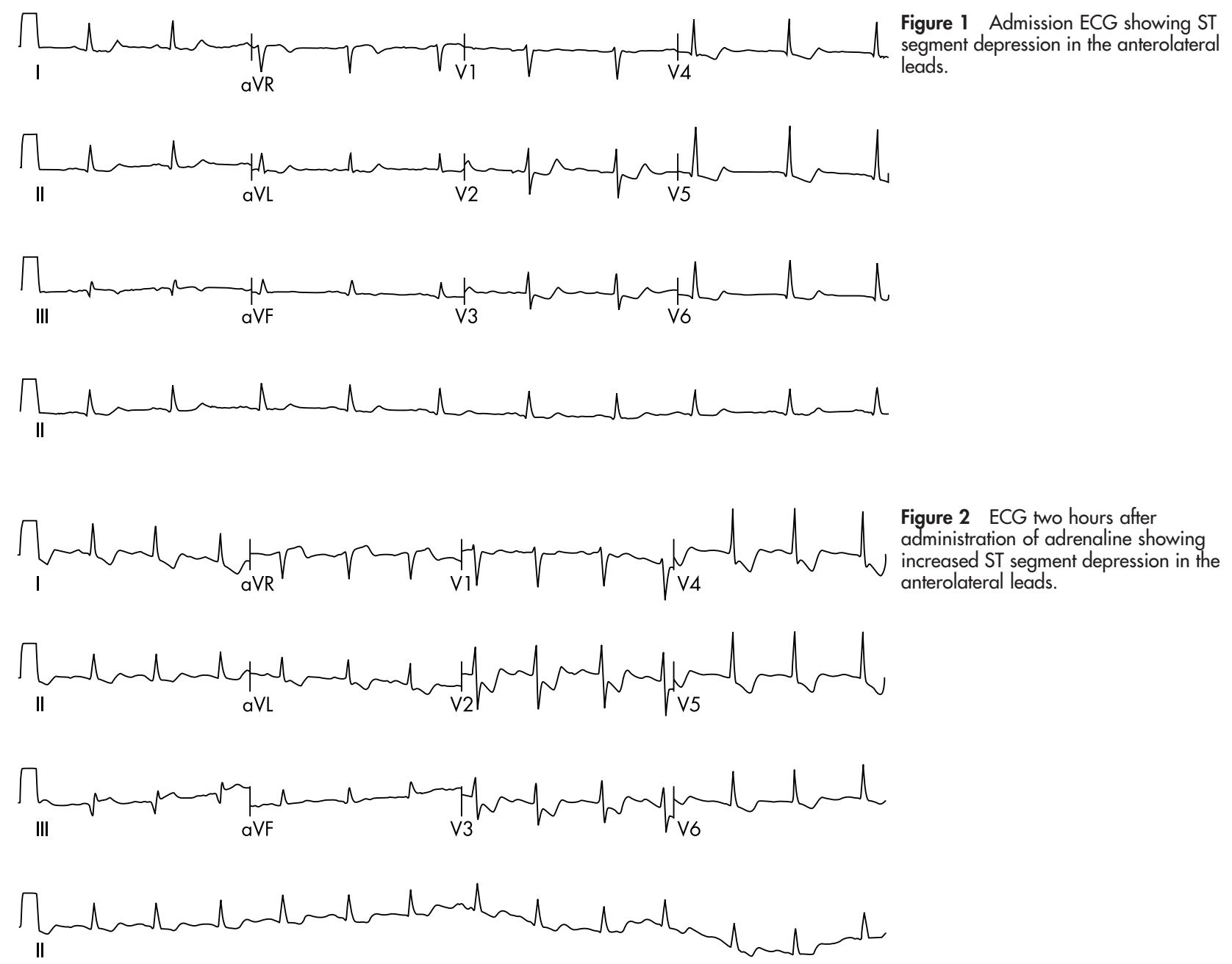

regarding the adverse reaction to enoxaparin and the incident was clearly recorded in his hospital records.

Cross reactivity between low molecular weight heparins (dalteparin sodium and enoxaparin) has been reported, manifesting as a skin reaction ${ }^{6}$ during prophylactic treatment for thromboembolism during pregnancy. Since neither product contains preservatives it is clearly due to the heparin component alone. Enoxaparin has been used safely after adverse reaction to unfractionated heparin (rash). This is surprising as enoxaparin is derived from porcine unfractionated heparin. ${ }^{7}$ It has been shown that patients may be tolerant of certain low molecular weight heparins but sensitive to others. ${ }^{1}$ It is recommended to confirm the diagnosis of true hypersensitivity that a patch, prick, or intradermal test should be performed initially for safety reasons. If these are negative, a subcutaneous test is necessary as it is the most reliable modality.

Anaphylaxis results from the rapid degranulation of mast cells and basophils. The term encompasses reactions that are IgE mediated (anaphylaxis) and those that are non-immunologically mediated (anaphylactoid). There is no clinical relevance between the two types of reaction. Reactions may be triggered by antibiotics, insect stings, foodstuffs, drugs, blood products, and anaesthetic agents.

Anaphylaxis may progress slowly or rapidly. Clinical expression is variable. Most common features are cardiovascular collapse, bronchospasm, cutaneous symptoms, angioedema, generalised oedema, or gastrointestinal symptoms. Diagnosis should be followed by removal of the inciting agent where possible. Prompt treatment with intramuscular adrenaline should follow. Supportive measures include airway support, oxygen therapy, intravenous antihistamine, and corticosteroids. Intravenous fluid and inotrope support may be required.

Adrenaline is regarded as the most important drug for any severe anaphylactic reaction. There is no international consensus on the recommended dose of adrenaline. ${ }^{8}$ Current UK Resuscitation Council guidelines support the use of $0.5 \mathrm{ml}$ of $1: 1000$ adrenaline to be administered intramuscularly. ${ }^{9}$ It is unclear as to why the attending doctor chose to prescribe the specified dose of adrenaline by the specified route.

The prescribed dose may need to be repeated on more than one occasion if clinical improvement is absent or if improvement is transient. It has been shown in trials that the intramuscular route produces significantly higher peak plasma concentrations compared with subcutaneous injection. ${ }^{10}$ The action of adrenaline can be detrimental by increasing myocardial oxygen consumption causing increased angina, myocardial ischaemia, and risk of myocardial infarction. ${ }^{11}$

\section{Authors' affiliations \\ L-A Smith, M Harkness, Friarage Hospital, Northallerton, UK}

Correspondence to: Dr Lesley-Ann Smith, Castle Hill Hospital, Castle Road, Cottingham, Hull HU16 5JQ, UK; smithla@doctors.org.uk

Submitted 12 November 2003

Accepted 26 March 2004 


\section{REFERENCES}

1 Bircher AJ, Itin PH, Tsakiris DA, et al. Delayed hypersensitivity to one lowmolecular-weight heparin with tolerance of other low-molecular-weight heparins. Br J Dermatol 1995;132:461-3.

2 Tonn ME, Schaiff RA, Kollef MH. Enoxaparin-associated dermal necrosis: a consequence of cross reactivity with heparin-mediated antibodies. Ann Pharmacother 1997;31:323-6.

3 Odeh M, Oliven A. Urticaria and angioedema induced low molecular weight heparin. Lancet 1992:340:972-3.

4 MacLaughlin EJ, Fitzpatrick KT, Jewell C. Anaphylactoid reaction to enoxaparin in a patient with deep venous thrombosis. Pharmacotherapy 2002;22:1511-15.

5 Kaur S, Thami GP, Srinivasan V, et al. Severe angioedema induced by angiotensin converting enzyme inhibitors: role of precipitating factors. J Dermatol 2002;29:336-8.
6 Phillips JK, Majumdar G, Hunt BJ, et al. Heparin-induced skin reaction due to two different preparations of low molecular weight heparin (LMWH). Br J Haematol 1993;84:349-50.

7 Smith RE, Townsend GE, Berry BR, et al. Enoxaparin for unstable angina and ancrod for cardiac surgery following heparin allergy. Ann Pharmacother 1996:30:476-80

8 Mclean-Toole APC, Bethune CA, Fay AC, et al. Adrenaline in the treatment of anaphylaxis: what is the evidence? BMJ 2003;327:1332-5.

9 UK Resuscitation Council. Emergency medical treatment of anaphylactic reactions for first medical responders and for community nurses. London: UK Resuscitation Council, January 2002

10 Simons FER, Gu X, Simons KJ. Epinephrine absorption in adults: intramuscular versus subcutaneous injection. J Allergy Immunol 2001;101:33-7.

11 Brown AFT. Therapeutic controversies in the management of acute anaphylaxis. J Accid Emerg Med 1998;15:89-95.

\section{Clinical Evidence-Call for contributors}

Clinical Evidence is a regularly updated evidence based journal available worldwide both as a paper version and on the internet. Clinical Evidence needs to recruit a number of new contributors. Contributors are health care professionals or epidemiologists with experience in evidence based medicine and the ability to write in a concise and structured way.

\section{Currently, we are interested in finding contributors with an interest in} the following clinical areas:

Altitude sickness; Autism; Basal cell carcinoma; Breast feeding; Carbon monoxide poisoning; Cervical cancer; Cystic fibrosis; Ectopic pregnancy; Grief/bereavement; Halitosis; Hodgkins disease; Infectious mononucleosis (glandular fever); Kidney stones; Malignant melanoma (metastatic); Mesothelioma; Myeloma; Ovarian cyst; Pancreatitis (acute); Pancreatitis (chronic); Polymyalgia rheumatica; Post-partum haemorrhage; Pulmonary embolism; Recurrent miscarriage; Repetitive strain injury; Scoliosis; Seasonal affective disorder; Squint; Systemic lupus erythematosus; Testicular cancer; Varicocele; Viral meningitis; Vitiligo However, we are always looking for others, so do not let this list discourage you.

\section{Being a contributor involves:}

- Appraising the results of literature searches (performed by our Information Specialists) to identify high quality evidence for inclusion in the journal.

- Writing to a highly structured template (about 2000-3000 words), using evidence from selected studies, within 6-8 weeks of receiving the literature search results.

- Working with Clinical Evidence Editors to ensure that the text meets rigorous epidemiological and style standards.

- Updating the text every eight months to incorporate new evidence.

- Expanding the topic to include new questions once every 12-18 months.

If you would like to become a contributor for Clinical Evidence or require more information about what this involves please send your contact details and a copy of your CV, clearly stating the clinical area you are interested in, to Claire Folkes (cfolkes@bmigroup.com).

\section{Call for peer reviewers}

Clinical Evidence also needs to recruit a number of new peer reviewers specifically with an interest in the clinical areas stated above, and also others related to general practice. Peer reviewers are health care professionals or epidemiologists with experience in evidence based medicine. As a peer reviewer you would be asked for your views on the clinical relevance, validity, and accessibility of specific topics within the journal, and their usefulness to the intended audience (international generalists and health care professionals, possibly with limited statistical knowledge). Topics are usually 2000-3000 words in length and we would ask you to review between 2-5 topics per year. The peer review process takes place throughout the year, and our turnaround time for each review is ideally 10-14 days.

If you are interested in becoming a peer reviewer for Clinical Evidence, please complete the peer review questionnaire at www.clinicalevidence.com or contact Claire Folkes(cfolkes@bmigroup.com). 